\title{
Impact of water demand management on sustainable water supply service delivery
}

\author{
S. Nyende-Byakika ${ }^{1}$, G. Ngirane-Katashaya ${ }^{2}$ \& J. M. Ndambuki ${ }^{1}$ \\ ${ }^{I}$ Department of Civil Engineering, \\ Tshwane University of Technology, South Africa \\ ${ }^{2}$ Water Resources Engineering and Management, \\ Makerere University, Uganda
}

\begin{abstract}
This paper analyses the impact of demand on water supply service delivery and demonstrates that the higher the demand, the lower the pressure at which water can be supplied. It highlights the notion that water is a finite resource and many regions in the world have neither sufficient surface nor groundwater reserves to meet all competing demands for water. Moreover, there normally exist capacity constraints in available water infrastructure. In such cases, withdrawals from water distribution networks have got to be controlled if sustainable water supply is to be achieved. Thus, water demand management should be accorded increased attention. The study assess the merits of rationing from a technical point of view and suggest that, if well managed, it stands out to be a viable water demand management strategy for water scarce areas. The authors also suggest that water supply should be managed from an equity point of view rather than an equality point of view.
\end{abstract}

Keywords: water supply, demand management, pressures, flows, rationing, equity.

\section{Introduction}

Water is a finite resource whose use should be regulated in order to conserve it. Climate change has led to reduced lake levels, rivers have dried up and rainfall levels have dropped in different parts of the world. All this calls for better water resources management in order to avoid its depletion, given that the rate at which water is used seems to exceed the rate at which it is replenished. Added to this is 
massive pollution of water bodies with untreated wastewater from industries which leaves even less potable water for consumption. Conflicts have arisen between countries, due to poor water sharing agreements, as different regions want to use more of the resource than others. In many cases, the cost of providing water supply is prohibitive as water sources are either polluted, or far off. In South Africa, for example, water supplied in the Gauteng region comes from the Lesotho highlands and the cost of transporting this water is exorbitant. Unfortunately, water being a basic human right and for public good, it is widely considered to be inexhaustible and is thereby used carelessly and wastefully. Public outcries arising from poor or no water service delivery are often made without due consideration of the scarcity of this resource.

Many water utilities struggle to fulfill share holder, regulatory, environmental and customer demands (Ray [1]) and in the face of increasing demands, have often appeared not to perform to expectations when in fact, in most cases the situation is beyond their control (Nyende-Byakika [2]), with specific reference to the National Water and Sewerage Corporation (NWSC) of Uganda. Established under the Water Statute of 1995, the Corporation is mandated to provide water supply and sewerage services in the urban centers of Uganda. The corporation currently operates in 22 towns in Uganda. The social and political responsibility carried by the corporation to provide water and sanitation services in the urban centers of Uganda, on the one hand, and the desire to maximise revenue on the other, has in combination with increased demand, led to excessive network expansions. However, the Corporation has increasingly faced service delivery challenges in various towns due to various reasons. For example, in Mbarara and Bushenyi towns in Western Uganda, water sources have dried up. Recently, the level of Lake Victoria dropped drastically by nearly two metres, and this threatened the supply of Kampala, Entebbe and Jinja towns whose water sources are in the lake. Moreover, the number of new water connections made increased by 58 percent from 14,045 in 2003/2004 to 22,218 in 2004/2005 (NWSC Annual Report [3]), a rate of growth that is expected to increase further with consumer growth. However as networks are expanded, cases of intermittent supply and little or no water have been increasingly reported in several areas. Areas that previously used to receive enough water are presently inadequately served.

Uganda is not the only country that faces water shortages but is among many countries whose water supply systems do not perform to the expectation of the public [4-11]. In this paper the authors demonstrate the importance of water resources management by hydraulically modelling a small distribution system and demonstrating that with increased demand loadings on the network, water supply diminishes and thus, water conservation should become part and parcel of daily living.

\section{Methods}

Methods that were undertaken in order to carry out this research included characterisation of the Rubaga subsystem of the Kampala Water Supply 
Network, development of a network model of the subsystem and analysis of responses of the model under various scenarios.

Data collected about Kampala Water included water produced and supplied in Kampala, pipe layout, pipe sizes and elevations, pipe lengths and materials, valves, reservoirs, pumps, consumption patterns (estimation of nodal demands) and pressures, heads and flows at strategic sections, well supplied zones and poorly supplied zones.

The second step entailed building a model of the Rubaga network in the EPANET2 hydraulic solver (Rossman [12] using the network data obtained. The modelling process involved network schematisation, model building, testing and problem analysis. Requirements needed to build the model included layout of the system i.e. pipe routes and junctions, and location of the main components. In addition, elevations of key sections were obtained as well as establishment of the fact that the Rubaga subsystem is essentially a gravity system, with pumping only existent at very remote sections.

Principal hydraulic input parameters for pipes are start and end nodes, diameters, lengths and roughness coefficients for determining headloss. Computed outputs for pipes included flow rate, velocity and headloss. The hydraulic head lost by water flowing in a pipe due to friction with the pipe walls was computed using the Darcy-Weisbach formula.

The Rubaga subsystem was modelled with 22 pipes and one $4000 \mathrm{~m}^{3}$ reservoir. A model of the Rubaga subsystem showing nodes with their elevations (masl) and Identification Numbers (ID) as well as pipe diameters (mm) is shown in Figure 1 (Nyende-Byakika et al. [13]).

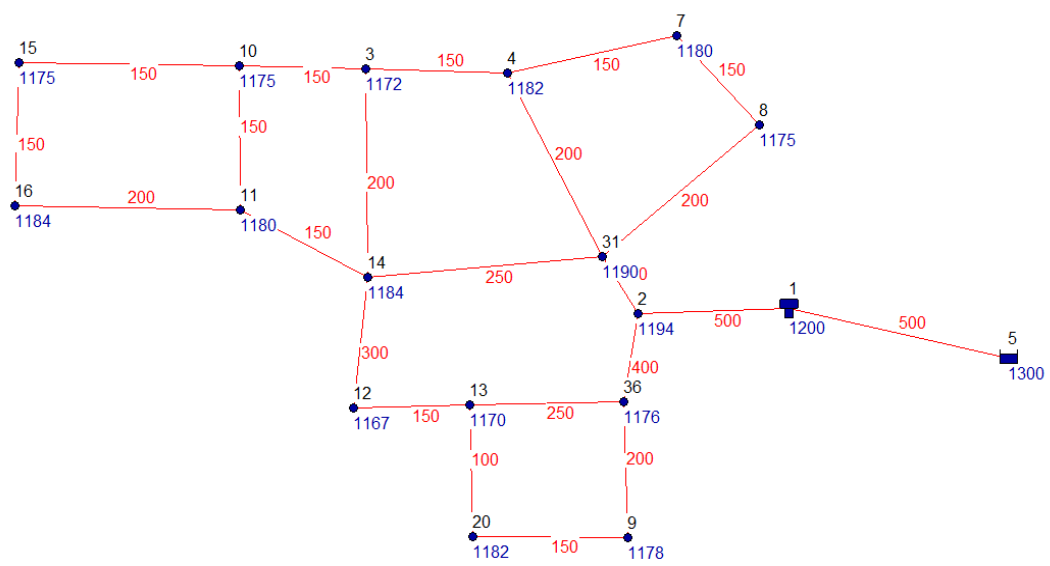

Figure 1: Model of Rubaga system showing node elevations, IDs and diameters.

Testing and calibration of the model of the existing system to field observed values was done for a range of operating conditions in order to evaluate the model's ability to represent actual situations. After adjustment of demand loadings and model parameters in order to reflect the reality on the ground, a 
comparison between field pressure values and model pressure values for Node 15 (Figure 1) is illustrated in Figure 2. It can be seen that there is good agreement between model values and field values.

Scenarios considered for research purposes involved putting different demand loadings onto the network with the aim of identifying what impact they had on system pressures in order to determine the relationship between demand and pressure. This is because the hydraulic solver employed for this research uses a demand-driven approach, whereby demands are model inputs while pressures are model outputs. Due to this, the model assumes that all input demands are satisfied, however, at varying pressures. Thus, in effect, pressure in this case, is the key indicator of consumer satisfaction and consequently, utility performance.

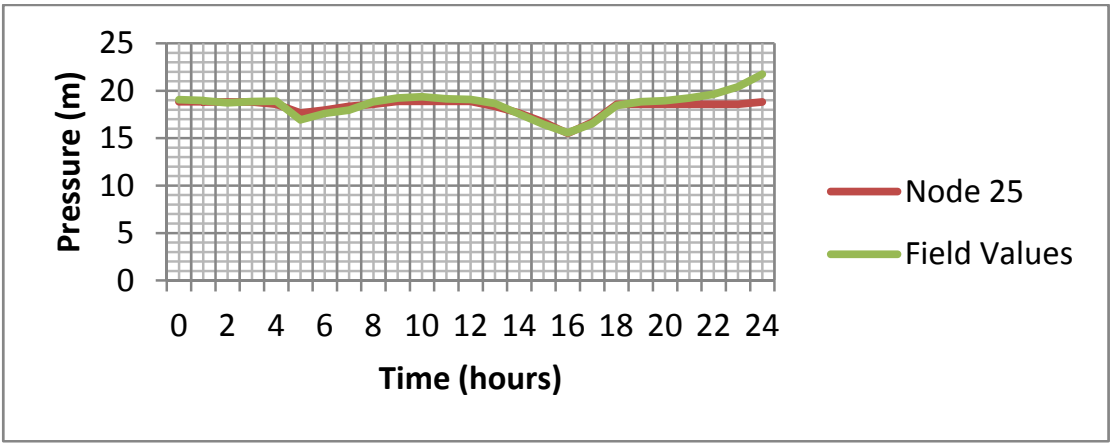

Figure 2: Comparison between field and model pressure outputs.

\section{Results}

In this section we looked at the response of nodal pressures to changing demand. Plots of variations of demand with pressure at node 24 were done at midnight (Table 1 and Figure 3) when demand is lowest and at 1600 hours (Table 2 and Figure 4) at peak demand. Demands were shown to be met at different pressures in a relationship of inverse proportionality whereby the higher the demands the lower the pressures at which the demands are fulfilled. When water abstracted from the system is a determinant of system performance, then more water withdrawn from the system increases headlosses and this directly lowers the pressure in the system.

It can be seen that for demand variation at midnight, pressures were much higher and varied gently because the demand was very low (Figure 3) and redundant demand in the system was very high so that changes in demand did not significantly affect the pressures at which the demand should be met. However, at 1600 hours, pressures were much lower and had a steeper slope. It is particularly observed that negative pressures developed at junction 16 highlighted in Figure 4, which implies an inability to meet that particular demand value at that node. 
Table 1: $\quad$ Pressure outputs for given demand values at midnight.

\begin{tabular}{|c|c|}
\hline Demand (1//s) & Pressure (m) \\
\hline 1.75 & 20.82 \\
\hline 2.00 & 20.81 \\
\hline 2.25 & 20.80 \\
\hline 2.50 & 20.79 \\
\hline 2.75 & 20.78 \\
\hline 3.00 & 20.77 \\
\hline 3.25 & 20.76 \\
\hline 3.50 & 20.75 \\
\hline 3.75 & 20.74 \\
\hline 4.00 & 20.73 \\
\hline 4.25 & 20.71 \\
\hline 4.50 & 20.70 \\
\hline 4.75 & 20.69 \\
\hline 5.00 & 20.67 \\
\hline 5.25 & 20.66 \\
\hline 5.50 & 20.65 \\
\hline 5.75 & 20.63 \\
\hline & \\
\hline
\end{tabular}

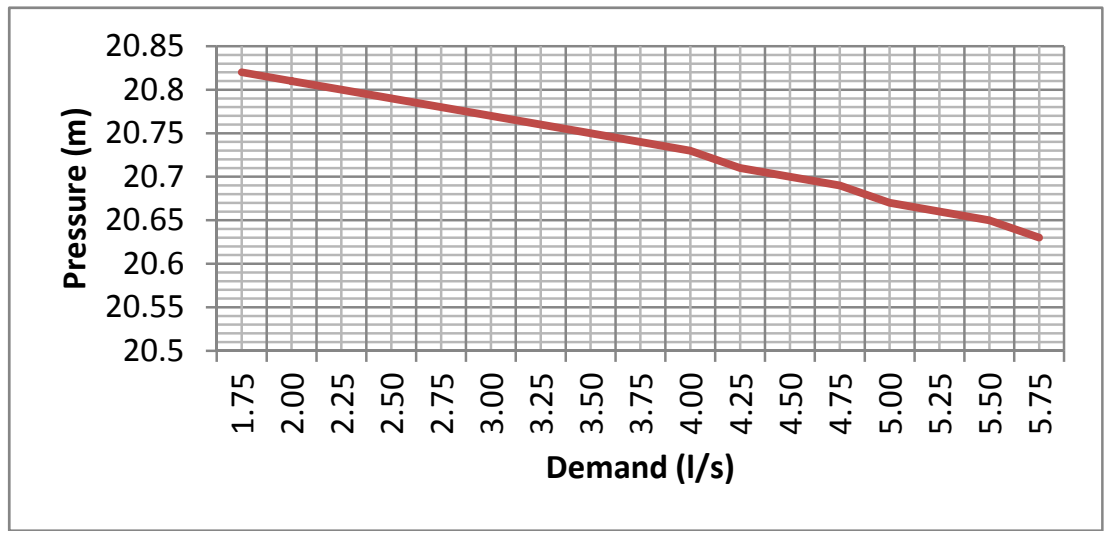

Figure 3: $\quad$ Plot of demand vs. pressure at node 16 at 1200 AM.

\section{Discussion}

From the results obtained, if water getting into the system is constant, then the higher the withdrawals from the system, the higher the headlosses and this lowers system pressures. Pressurisation occurs at a rate proportional to the net head and discharge i.e., difference between input discharge and output discharge (supply). To improve the rate of pipeline pressurisation and enable customers to get some water; therefore, it makes sense to improve pipe discharge by limiting output discharge or withdrawals from the network (nodal demand) as well as flow in other links connecting to the node. This is due to the Principle of 
Table 2: $\quad$ Pressure outputs for given demand values at 1600 hours.

\begin{tabular}{|c|c|c|c|}
\hline Demand (l/s) & Pressure (m) & Demand ( $(1 / \mathbf{s})$ & Pressure (m) \\
\hline 8.75 & 17.51 & 41.25 & 10.52 \\
\hline 10.00 & 17.33 & 42.50 & 10.16 \\
\hline 11.25 & 17.14 & 43.75 & 9.79 \\
\hline 12.50 & 16.94 & 45.00 & 9.42 \\
\hline 13.75 & 16.74 & 46.25 & 9.05 \\
\hline 15.00 & 16.53 & 47.50 & 8.66 \\
\hline 16.25 & 16.31 & 48.75 & 8.27 \\
\hline 17.50 & 16.08 & 50.00 & 7.88 \\
\hline 18.75 & 15.85 & 51.25 & 7.48 \\
\hline 20.00 & 15.61 & 52.50 & 7.07 \\
\hline 21.25 & 15.36 & 53.75 & 6.66 \\
\hline 22.50 & 15.11 & 55.00 & 6.24 \\
\hline 23.75 & 14.85 & 56.25 & 5.81 \\
\hline 25.00 & 14.58 & 57.50 & 5.38 \\
\hline 26.25 & 14.31 & 58.75 & 4.94 \\
\hline 27.50 & 14.03 & 60.00 & 4.50 \\
\hline 28.75 & 13.74 & 61.25 & 4.04 \\
\hline 30.00 & 13.45 & 62.50 & 3.59 \\
\hline 31.25 & 13.15 & 63.75 & 3.13 \\
\hline 32.50 & 12.84 & 65.00 & 2.66 \\
\hline 33.75 & 12.53 & 66.25 & 2.18 \\
\hline 35.00 & 12.21 & 67.50 & 1.70 \\
\hline 36.25 & 11.88 & 68.75 & 1.22 \\
\hline 37.50 & 11.55 & 70.00 & 0.72 \\
\hline 38.75 & 11.21 & 71.25 & 0.23 \\
\hline 40.00 & 10.87 & 72.50 & -0.28 \\
\hline
\end{tabular}

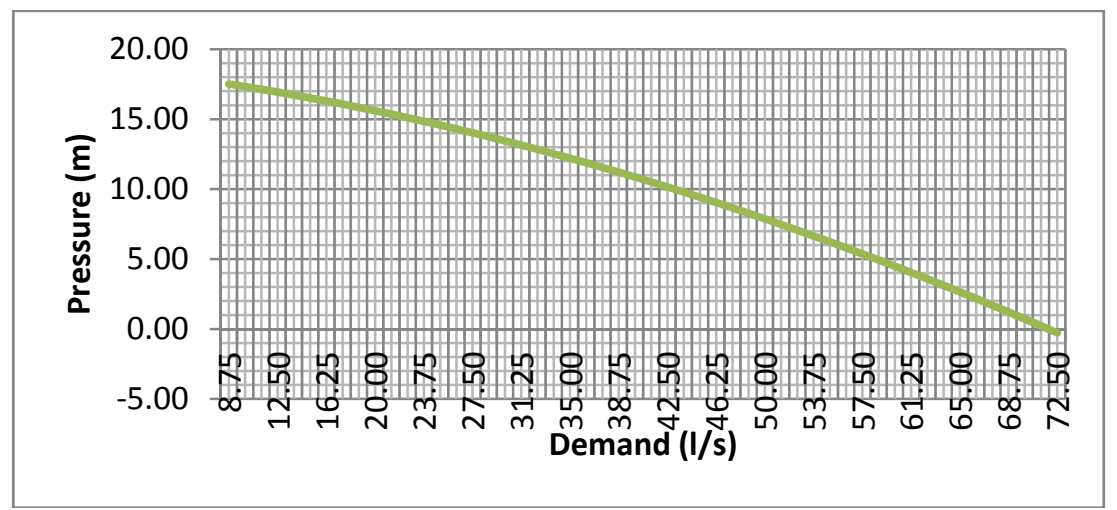

Figure 4: $\quad$ Plot of demand vs. pressure at node 16 at 1600 hours. 
Conservation of Mass which implies that flow into the node equals flow out of the node. In Figure 5 for example, the principle is obeyed since node inflows are equated to node outflows (flow out of the node also includes withdrawals from the network). At the highlighted node in which $3.50 \mathrm{l} / \mathrm{s}$ is withdrawn from the network,

Flows out of the node $(1 / \mathrm{s})=3.50+9.41+11.66=24.57$

Flows into the node $(1 / \mathrm{s})=3.84+20.73 \quad=24.57$

It can be inferred therefore that if flow out of the node is controlled, this can improve the discharge in the input links.

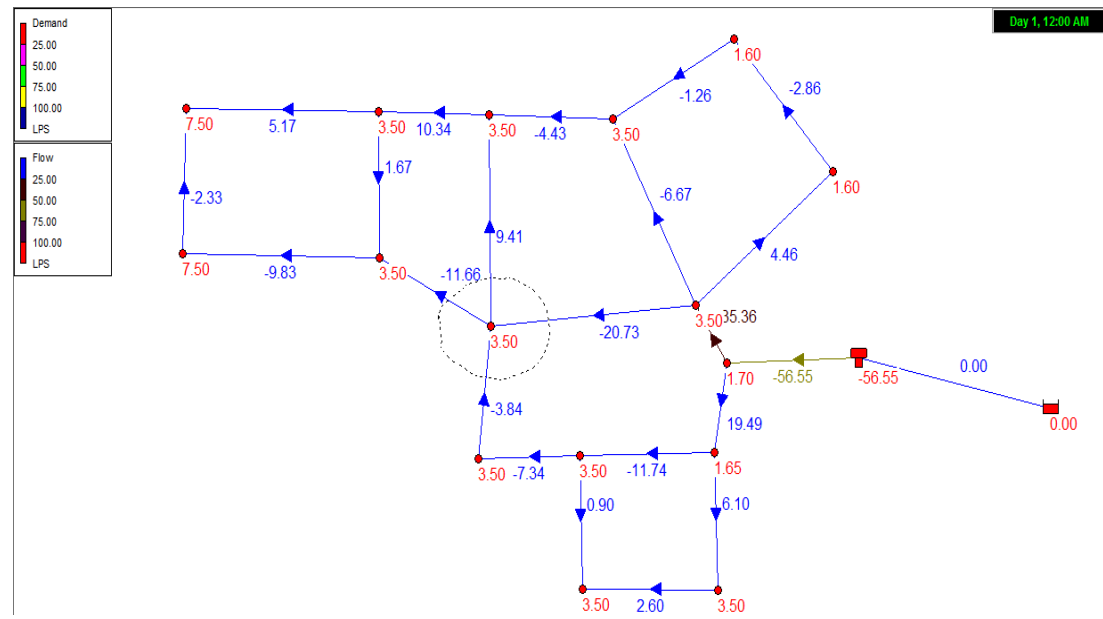

Figure 5: Link flows and Nodal demands in Rubaga subsystem.

Figure 5 also reveals that the summation of all nodal demands in the subsystem (withdrawals from the network, arrows indicate direction of flow, if negative sign is ignored) equals the flow from the tank into the system (Table 3 ) i.e. $56.55 \mathrm{l} / \mathrm{s}$ thus if external withdrawals are limited, pressurisation is facilitated and better pressures are obtained in the system. In order to achieve this, demands have got to be controlled.

It is worth noting that these significant changes in pressure would not occur if there was an infinite supply of water, however, water is a finite resource. They would also not occur if the carrying capacity of the infrastructure was unlimited, but it is limited by the magnitude of capital investments that can be financed. Thus, it is important for us to control the use of water.

Water use control can be achieved through various water demand management techniques. For example, it is advisable to gazette geographical areas of service for a particular network and not add more settlements on the system, as this increases demand. 
Table 3: $\quad$ Node demand and system feeder tank withdrawals.

\begin{tabular}{|c|c|}
\hline Node ID & Demand (1/s) \\
\hline 2 & 1.70 \\
\hline 14 & 3.50 \\
\hline 20 & 3.50 \\
\hline 31 & 3.50 \\
\hline 36 & 1.65 \\
\hline 12 & 3.50 \\
\hline 13 & 3.50 \\
\hline 3 & 3.50 \\
\hline 4 & 3.50 \\
\hline 7 & 1.60 \\
\hline 8 & 1.60 \\
\hline 9 & 3.50 \\
\hline 10 & 3.50 \\
\hline 11 & 3.50 \\
\hline 15 & 7.50 \\
\hline 16 & 7.50 \\
\hline Total & 56.55 \\
\hline $\begin{array}{c}\text { Tank } \\
\text { Withdrawal }\end{array}$ & 56.55 \\
\hline
\end{tabular}

In addition, water distribution is underlain by a systems analysis concept (Biswas [14]) whereby interrelationships between different aspects of the network play a fundamental role in system behavior. Thus, changes in demand at one node in a network do not only affect the pressure at that node, but can affect pressures at other points in the network as well. The reverse is also true, that reduction in withdrawals at some sections of the network can lead to improvements in pressure at other sections.

Therefore, every action taken should be critically assessed for its global impact. Due to the non linear nature of equations of continuity and energy that govern water distribution, it is not easy to relate cause and effect; however, this is made possible using computer models. Fortunately, through rationing, this phenomenon can be exploited to the advantage of water utilities by deliberately limiting withdrawals in some parts of the network at pre-determined periods in order to supply other sections of the network. If well, managed, a program can be drawn and the public sensitised about this operation in order to receive acceptance. This can be a pragmatic water demand management tool based on equity and not equality of need, and can serve to provide a satisfactory service as consumers will be compelled to budget for the resource.

Operationally, rationing of water supply can be done by utilising valve action through, for example, closing off certain valves at different times of the day 
either completely or partially. Another approach is by use of economic instruments such as different tariffs for different periods at different sections of the network in order to discourage overuse of the resource in particular situations while encouraging its use in other situations. While this calls for sophisticated operations, the tremendous advantages that Information Technology brings can be borrowed in order to design programs that ensure the feasibility of these tactics.

\section{Conclusions}

The authors discovered that with increased demand in a water-limited facility, network pressures decline and this can cause consumer dissatisfaction arising from failure to access water. In the wake of water resource constraints and infrastructural limitations, it is important to utilise the available resource as sustainably as possible. This calls for proper water demand management.

The authors highlighted possible water demand management techniques that can be used and especially assessed the merits of rationing from a technical point of view, suggesting that if well managed, it stands out to be a viable water demand management strategy for water scarce areas. It calls for a lot of discipline but if the public is sensitised about it and accepts, it can yield very satisfactory results. Water Supply should be managed from an equity point of view and not an equality point of view.

Future research should focus on more water demand management techniques for water scarce areas in order to ensure sustainability of the very important water resource.

\section{References}

[1] Ray C.F., The Use of GIS in a major water utility company. Proceedings of the Institution of Civil Engineers, 114 (2), 1996.

[2] Nyende-Byakika S., Modelling of Pressurised Water Supply Networks that may exhibit Transient Low Pressure-Open Channel Flow Conditions. PhD Thesis. Vaal University of Technology. South Africa. 2011.

[3] NWSC. Annual Report. Kampala. 2006/2007.

[4] Zyoud, S.H.A.R., Hydraulic performance of Palestinian water distribution systems. MSc Thesis. An-Najah National University. Palestine. 2003.

[5] Lee, E.J. \& Schwab, K.J., Deficiencies in drinking water distribution systems in developing countries. Journal of Water and Health, 3(2), 2007.

[6] Vairavamoorthy, K., Cities of the future and urban water management. Paper presented during Thematic Week 2: Water and City. Water Tribune Zaragoza International Exhibition. 2008.

[7] Vairavamoorthy, K., Gorantiwar, S.D. \& Pathirana, A., Managing urban water supplies in developing countries - Climate change and water scarcity scenarios. Physics and Chemistry of the Earth, 33(5), pp 330-339. 2008.

[8] Basu, S. R. \& Main, H. A. C., Calcutta's water supply: demand, governance and environmental change. Applied Geography, 21 (1), pp 23-44, 2001. 
[9] Biswas, A. K. \& Seetharam, K. E., Achieving water security for Asia. International Journal of Water Resources Development, 24(1), pp 145 176, 2008.

[10] Rosenberg, D.E., Integrated water management and modelling at multiple spatial scales. PhD Thesis. University of California Davis. 2008.

[11] Khatri, K.B. \& Vairavamoorthy, K., Challenges for urban water supply and sanitation in developing countries. Discussion draft paper for the Session on Urbanisation. UNESCO-IHE. The Netherlands.

[12] Rossman, A.L., EPANET Users' Manual. National Risk Management Laboratory. United States Environmental Protection Agency, Ohio. 2000.

[13] Nyende-Byakika, S., Ngirane-Katashaya G. \& Ndambuki, J.M., Behaviour of stretched water supply networks. Nile Water Science and Engineering Journal, 3(1), 2010.

[14] Biswas, A. K., Systems Approach to Water Management. New York: McGraw-Hill, 1976. 